\title{
PERFORMANCE EVALUATION OF COLD RECYCLING EXPERIMENTAL STRETCH CONSTRUCTED WITH RBI-GRADE-81 AT BANGALORE UNIVERSITY
}

\author{
Ayyanna Habal ${ }^{1}$, Kavya $\mathbf{P}^{2}$, Amarnath $\mathrm{MS}^{3}$ \\ ${ }^{1,2}$ M E Student, ${ }^{3}$ Professor, Department of Civil Engineering, UVCE Bangalore University Bangalore, \\ ayyanna007@gmail.com, amaranth_ms@rediffmail.com
}

\begin{abstract}
The bituminous pavement rehabilitation alternatives are mainly overlaying, recycling and reconstruction. In the recycling process the material from deteriorated pavement, known as reclaimed asphalt pavement (RAP), is partially or fully reused and it is a valuable approach for technical, economical, and environmental reasons. Full Depth Reclamation (FDR) is one of the cold methods of recycling the bituminous pavements. In this study an experimental stretch is selected for FDR in which the full flexible pavement section and a predetermined portion of the underlying materials are milled and remixed with about $10 \%$ of $10 \mathrm{~mm}$ down size aggregate and $30 \%$ stone dust to match the Bituminous Concrete (BC) Grade-I mix limits and known quantity of RBI 81 stabilizer. Stabilization of RAP material with RBI grade 81 reduces the requirement of new materials, time of construction and increases the strength of the road. This report consist of a case study of road constructed at Jnanabharathi campus, Banglore University, which include assessment of existing pavement condition and the preparation of pavement surface for the construction of stabilized layer and construction aspects of pavement using RAP material stabilized with RBI grade 81. The report also presents results of some short term functional and structural condition studies on the study stretch. From the limited studies carried out it is concluded the RAP material can be used effectively by the stabilization with RBI grade 81. From the field studies it is concluded that the strength of the pavement increases with increase in RBI grade 81 dosages.
\end{abstract}

Keywords: Stabilization of Reclaimed Asphalt Pavement (RAP), RBI Grade 81, Full Depth Reclamation, Cold in Place Recycling (CIR).

\section{INTRODUCTION}

The existing large network of roads contains millions of tonnes of high quality aggregate and asphalt. The increase in road construction activity has resulted depletion of good quality materials like soil and aggregates and increase in highway construction cost. The widely used rehabilitation method of just overlaying aged and cracked pavement cannot be justified from an economic and engineering stand point.

One of the cost saving measures is asphalt recycling which results in saving materials, labour and energy in many projects. As petroleum products and quality of aggregate become scarce, recycling of pavements may be a better option.

Cold in-Place Recycling (CIR) is defined as a rehabilitation technique in which the existing materials of pavement are re used in place. The current state of the art for cold recycling asphalt pavement is only about $10-15$ years old. Some of the short term performance studies carried out in other countries has been so promising that CIR is growing rapidly. Generally CIR has been found to be economical, environmentally friendly. They are effective in asphalt pavement rehabilitation method for many types of distresses.
In cold in-place recycling, the existing damaged asphalt layer is pulverized, mixed together with existing base. The residual asphalt acts as an excellent binder to help make the recycled base waterproof. Addition of chemical stabilizer may further upgrade the recycled base by increasing the load carrying capacity of the pavement structure. In the present study RBI Grade- 81 is used as the stabilizer. CIR is suitable for roads which have been built over the years with layers of surface treatments. Recycled cold mix provides a good base which can be overlayed with asphalt surface to provide a durable riding surface.

The objective of the study is to evaluate the performance of cold in place recycled experimental stretch constructed with RBI-81 Stabilizer.

\section{REVIEW OF LITERATURE}

NCHRP Synthesis 421 (2011) the studies were carried out for different type of in place recycling process, the type, severity, and extent of distresses are used to identify the most useful in-place recycling method. Climate conditions, roadway geometry and features need to be considered during in-place recycling project selection. 
Misra et al (2007) studied about Full-Depth Cold in-Place Recycling (CIR) with self-cementing fly ash been shown to be an effective method of converting conglomerate pavement sections into durable roads.

Satander Kumar et al (2010) studied the soil and aggregate stabilization using RBI grade 81 stabilizers for subgrade and base layer For checking the suitability of RBI Grade 81 stabilized materials as a base layer, compressive Strength and Elastic Modulus tests are performed on a sample of mixture of $50 \% 10 \mathrm{~mm}$ down aggregate $+50 \%$ Stone dust. Dosage of $4 \%, 6 \%$ and $8 \%$ of RBI grade 81 by weight of the sample are used in these testing. Compressive Strength and Elastic Modulus of samples increases with increase in number of days of curing and dosage of RBI Grade 81. Satander Kumar et al have drawn a conclusion that Strength requirement for sub base layer is satisfied by the tested samples. Hence RBI grade 81 stabilized layers are suitable as Sub Base Layer.

Thammavong et al (2006) et al presented the result of a laboratory evaluation of cement stabilized on reclaimed asphalt pavement aggregate. The reclaimed asphalt pavement aggregate consists $25 \%$ of asphaltic concrete and $75 \%$ of old base course. The AASHTO method is adopted to determine and evaluate Unconfined Compressive Strength (UCS), Indirect Tensile Strength (ITS) and resilient modulus (MR). The tests were conducted on type I Portland cement using 2, 3, 4, and 5\% weight of RAP materials with the curing duration of 7,14 and 28 days. As the results, the strength of the RAP aggregate increased with the increasing of cement content and curing time. The specimens prepared for ITS study consist of $2 \%, 3 \%, 4 \%$, and $5 \%$ cement content for 7, 14 and 28 days cured. The results indicate that the percentage of cement increased up to $10 \%$ RAP strength and the specimens with longer curing period has increased the strength too. Hence, percentage and curing duration have affect to the cement stabilized. The test result indicated the resilient modulus values increased while increments cement content and curing time

Taha et al studied laboratory evaluation of RAP and RAPvirgin aggregate mixtures as road base and sub-base materials at Oman, Physical, compaction, and California bearing ratio tests were conducted on the following RAP/virgin aggregate blends: 100/0, 80/20, 60/40, 40/60, $20 / 80$, and $0 / 100 \%$. Initial results indicate that RAP could be expected to replace virgin aggregate in the pavement sub- base structure with satisfactory results if the RAP material were mixed with virgin aggregate. Best results were obtained for the 60/40, 40/60, 20/80, and 0/100 \% RAP/virgin aggregate blends. Higher dry density and CBR values are obtained as virgin aggregate content is increased. Based on a comparison with standard paving materials used in the Sultanate of Oman roads the stabilized RAP material appears to be able to function as well as a conventional subbase material.

\section{PRESENT INVESTIGATIONS}

\subsection{Selection of Study Stretch}

A $250 \mathrm{~m}$ stretch of main road in Jnanabharathi Campus of Banglore University in front of Civil Department is selected for Full Depth Reclamation (FDR) using RBI grade 81 stabilizer. The pavement section consists of two lanes LHS (from Jnanabharathi Gate towards Quarters) of four lane divided carriageway passing through plain/rolling terrain of Banglore University campus, Banglore.

\subsection{Condition Survey of Existing pavements}

The surface condition and existing drainage condition of the study stretch were assessed by visual observation. The existing pavement surface did not have proper camber. The longitudinal drains and shoulder drains are choked by vegetation and silt deposition.

The stretch under study was badly damaged with many distresses like cracking, ravelling and large potholes. At many locations the surface course is disintegrated exhibiting poor riding. The existing pavement section was cut open near the edge and pavement thickness was measured.

\subsection{Description of Study Stretch}

The study stretch selected is $250 \mathrm{~m}$ long and $10 \mathrm{~m}$ wide stretch in front of Civil Engineering Department, Jnanabharathi Campus, Bangalore University, Bangalore. This is the main road of University which connects Mysore road with outer ring road. The study stretch is divided into three sub-sections of length 50, 100 and $100 \mathrm{~m}$. Based on the limited studies carried out by various researchers on stabilization of aggregates/RAP using RBI grade 81 stabilizer, the strength increases with increase in dosage of RBI grade 81 . Hence the dosage of RBI grade 81 stabilizer is fixed as $4 \%, 5 \%$ and $6 \%$ for various sub-sections. The details of test section are shown in Fig.1.

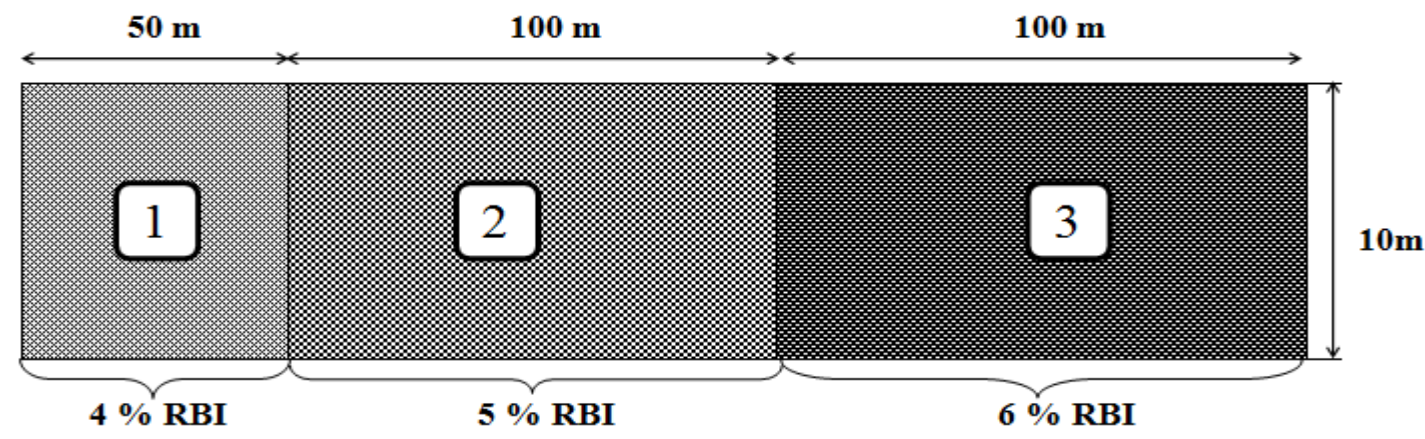

Fig. 1 Plan showing different Sub-sections of the study stretch 


\section{CONSTRUCTION OF TEST SECTION}

\subsection{Preparation of existing section}

Full depth reclamation process is adopted for the preparation of existing section. Prior to the construction of the stabilized layer the existing layer is scarified to required depth with the use of suitable equipment like milling machine. Any oversized material $\left(>1 / 3^{\text {rd }}\right.$ the thickness of the layer to be stabilized) was removed. The Scarification process and scarified layer is shown in Fig. 2.

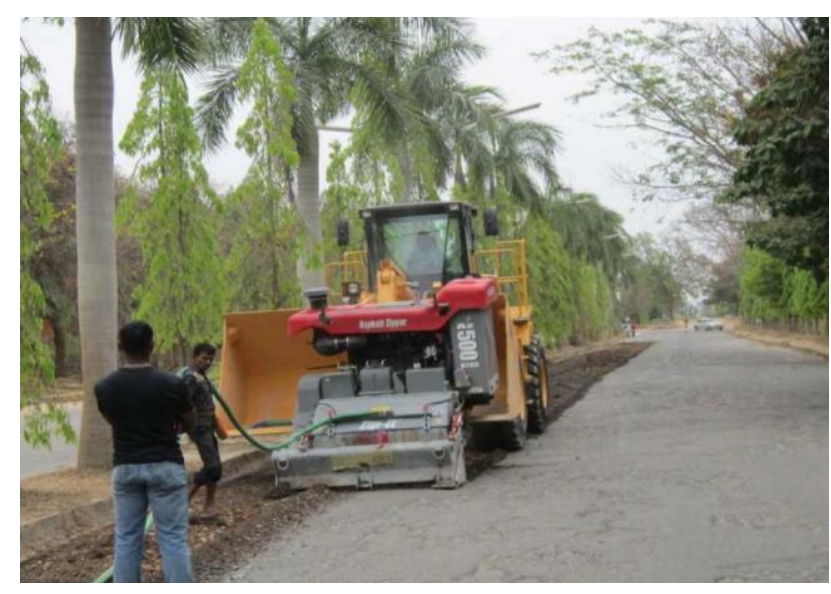

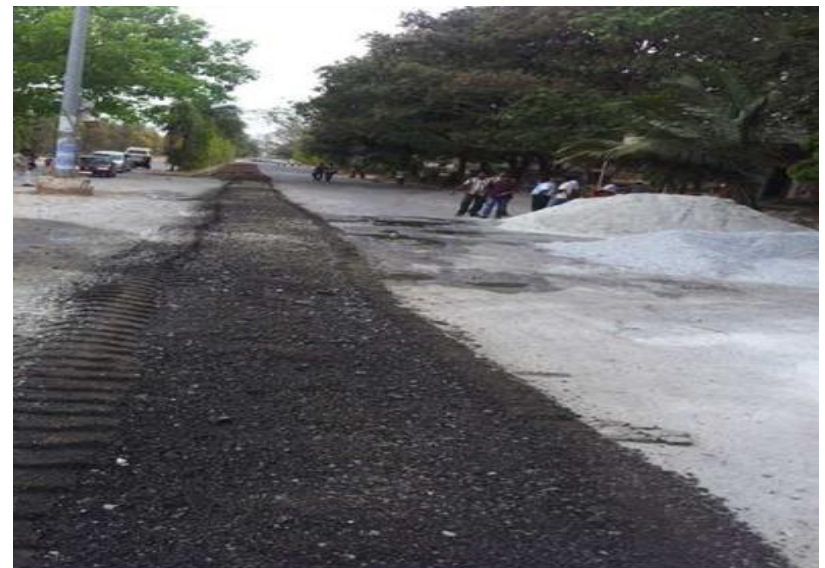

Fig. 2 Scarification process and scarified layer

\subsection{Spreading material}

After scarification and pulverization of the existing section, about $10 \%$ of $10 \mathrm{~mm}$ down size virgin aggregate and $30 \%$ stone dust is added to match the BC Gr-I limits and spread uniformly using suitable equipment like grader throughout the section. Then the materials are mixed thoroughly with the help of rotovator. Then dosage of RBI Grade 81 varied from 4 to $6 \%$ in sections 1,2 and 3 respectively and spread by calculating the area required for spreading one bag of 20 $\mathrm{kg}$ RBI-81. The blocks are marked in the section so it will be easier for the labours to spread one bag of RBI for one block to maintain the dosage. The application of RBI grade 81 is shown in Fig. 3.

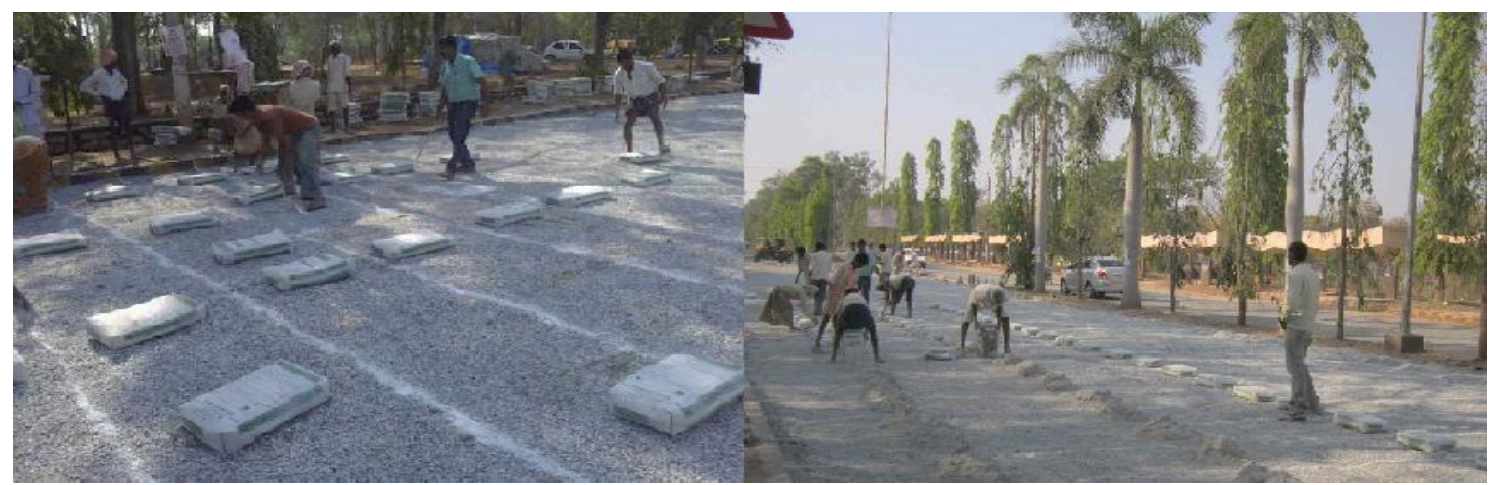

Fig. 3 Application of RBI grade 81

\subsection{Dry mixing}

Immediately after the product has been spread it was mixed with material to the full depth of treatment. Special attention was taken not to disturb the compacted layer underneath and especially not to mix the stabilizing agent below the desired depth. Mixing was continued to ensure homogeneity and thorough mixing of the material with RBI Grade81 over the full area of the application site.

\subsection{Watering}

The water required (OMC) is added and mixed with the material being treated within the prescribed period to enable compaction to be completed. Uniform mixing of the product and water was ensured success of the stabilized layer.
Immediately after RBI Grade 81 has been properly mixed into the layer, the pre-determined optimum moisture content (OMC) determined by laboratory studies was administered. Care was taken to ensure that the moisture content of the mixture is not below the OMC or more than $2 \%$ above the OMC that causes the roadbed to become unstable during compaction and finishing.

\subsection{Wet mixing}

After watering wet mixing was done using a rotovator (soil recycler) or Milling machine over successive passes of the layer. Specific attention was given to ensure that the mixing was uniform. Dry Mixing of RBI Grade 81, Watering process and Wet Mixing Process are shown in Fig. 4. 

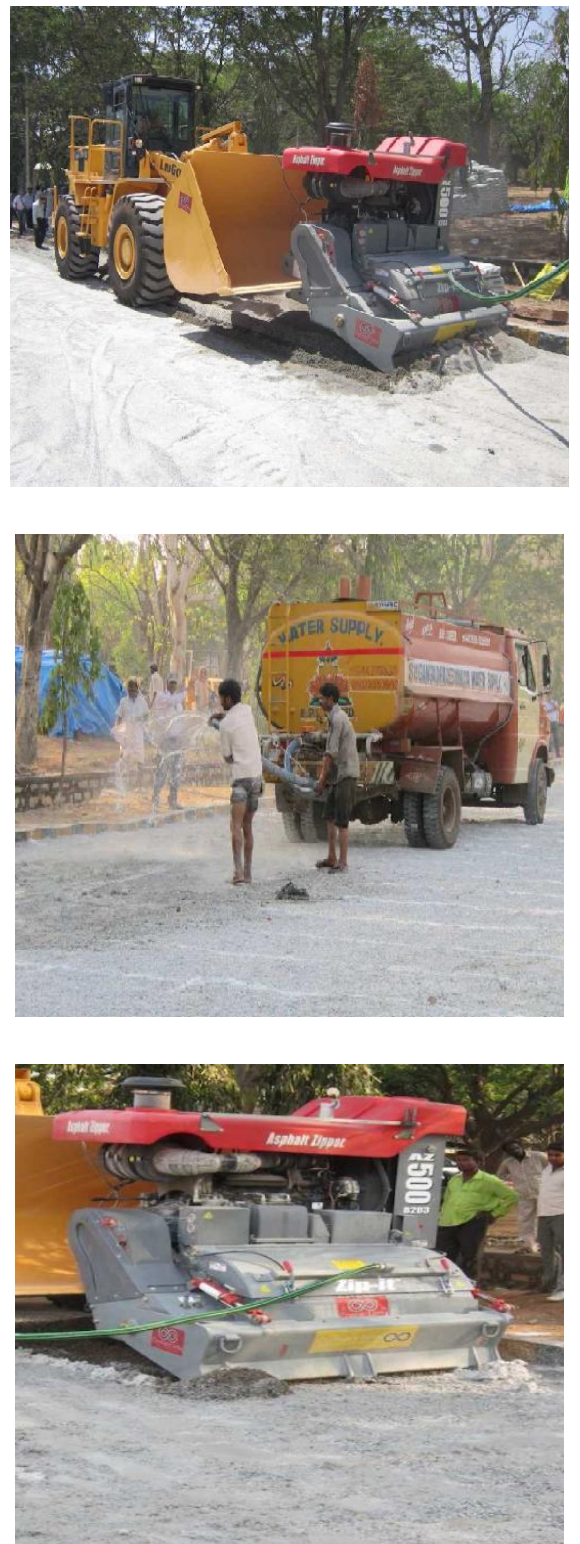

Fig. 4 Dry Mixing of RBI Grade 81, Watering and Wet Mixing Process

\subsection{Compaction}

Compaction of the material in the pavement layer was carried out within 4 hours, to ensure that specified densities are obtained without damage being done to lower layer structures. The compacted layer was provided with suitable camber to prevent standing water from scouring the completed work. Compaction was carried out in a series of continuous operations covering the full width of the layer. During compaction, the layer was maintained to prevent loss of moisture from evaporation by further light applications of water over the surface. The minimum compaction required was maintained at $98 \%$ of Modified AASHTO density.

\subsection{Tack Coat Application}

After finishing the construction of stabilized layer for the study stretch tack coat is applied using Rapid Setting-1 Emulsion.

\subsection{Application of SDBC Surface Course}

The study stretch is surfaced with $25 \mathrm{~mm}$ thick SDBC using paver and then compacted with vibratory roller and then final rolling was done with pneumatic tyred roller (PTR).

\subsection{Quality control tests}

During the construction of the test section quality control tests like Gradation, OMC, field Density are checked. After the construction, surface finish is checked and if any irregularities are there then immediately rectified. The construction of experimental stretch was completed in March 2012.

\section{PERFORMANCE EVALUATION}

\subsection{Visual Condition Study}

Visual assessment of pavement surface condition was carried out for the entire stretch comprising of sub sections treated with RBI-81 stabilizer. It was observed that the surface condition of test stretch is good after six months of traffic and one monsoon season.

\subsection{Measurement of Pavement Surface Condition using MERLIN}

The longitudinal unevenness of a road surface is a measure of the road condition and an important factor in determining vehicle operating costs. It is usually measured on a standard roughness scale such International Roughness Index (IRI). The unevenness of the study stretch is measured using Measurement of Roughness using Low cost Instrument (MERLIN). Roughness Index or as measured by a towed fifth wheel bump integrator, can then be determined using following equations.

$$
\begin{aligned}
& \text { IRI }=0.593+0.0471 \mathrm{D} \quad \mathrm{m} / \mathrm{km} \\
& \mathrm{UI}=\mathbf{6 3 0}(\text { IRI })^{1.12} \mathrm{~mm} / \mathrm{km}
\end{aligned}
$$




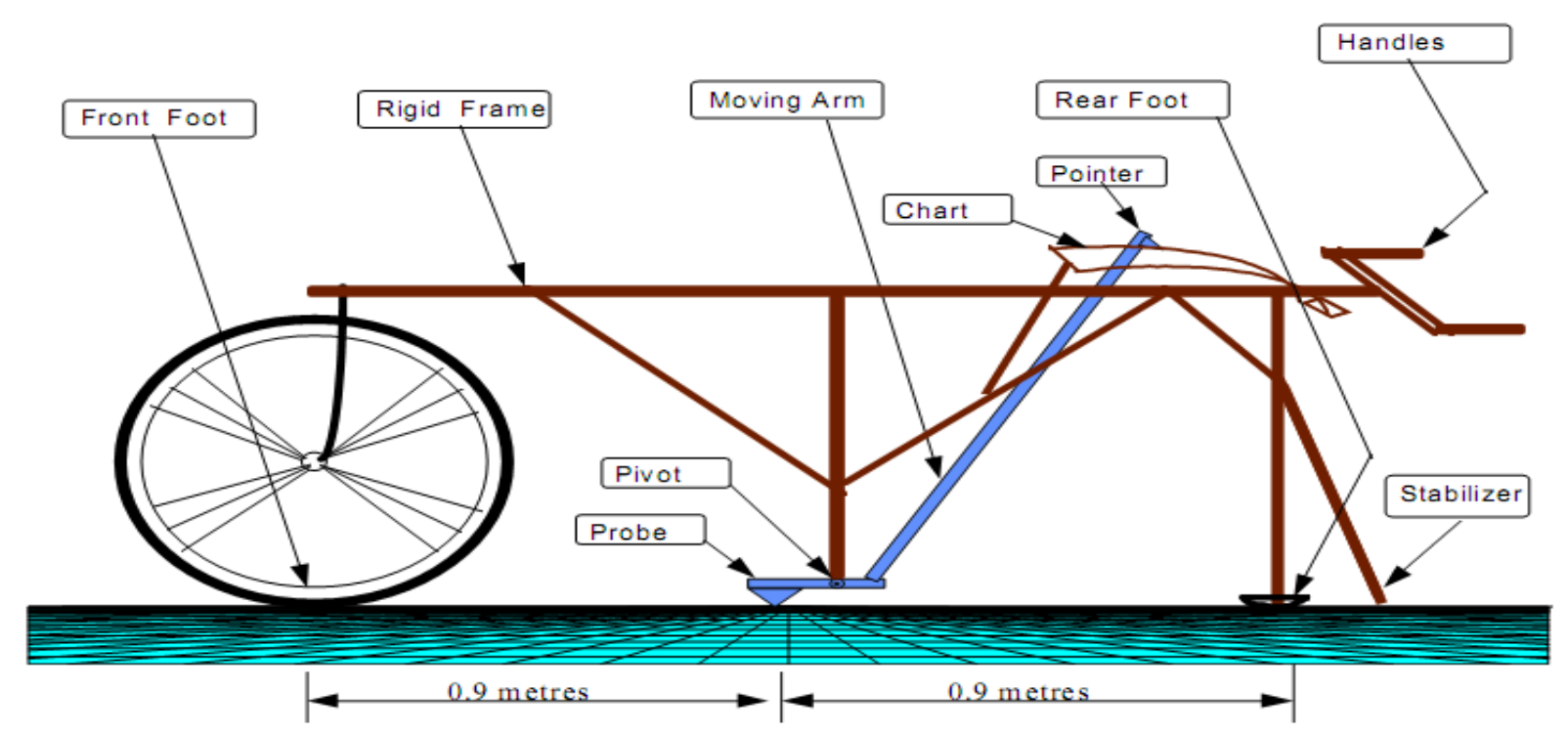

Fig. 5 The Schematic of the MERLIN.

Table. 1- Results of Roughness study

\begin{tabular}{|c|c|}
\hline Sequence & $\begin{array}{c}\text { Unevenness } \\
\text { Index, } \\
\mathbf{m m} / \mathbf{k m}\end{array}$ \\
\hline I Cycle & 2320 \\
\hline II Cycle & 2500 \\
\hline
\end{tabular}

\subsection{Evaluation of Pavement Structural Condition}

In the present study, the structural condition of pavement is evaluated by using i) Geogauge, ii) Dynamic Cone Penetrometer and iii) Benkelman Beam Deflection.

\section{Using Geo-Gauge}

Geogauge is an instrument used to measure stiffness and elastic modulus of pavement layer and also to estimate the field CBR value. The instrument is placed on the pavement surface by clearing the loose soil on the surface. In case of coarse aggregate, hard surfaces or stiff clay may require moist sand to be patted on the surface for good direct contact with the foot. Ensure the gauge has clearance on the side and bottom, does not come into contact with a trench wall, pipe, soil, etc. Then turn on the geogauge, the stiffness and elastic modulus are displayed on digital indicator within two minutes. This can also be used to monitor/reduce the variability of strength from $230-310 \mathrm{~mm}$ depth from surface during pavement construction.

\section{Using Dynamic Cone Penetrometer (DCP)}

The Dynamic Cone Penetrometer is a simple device developed in UK for rapid in situ strength evaluation of subgrade and other unbound pavement layers. Essentially, a DCP measures the penetration of a standard cone when driven by a standard force, the reported DCP value being in terms of the penetration of the standard cone, in $\mathrm{mm}$ per blow of the standard hammer. The standard steel cone with an angle of $60^{\circ}$ has a diameter of $20 \mathrm{~mm}$. the standard $8 \mathrm{~kg}$ drop hammer slides over a $16 \mathrm{~mm}$ dia steel rod with a fall height of $575 \mathrm{~mm}$.

Basically, the penetration (in $\mathrm{mm}$ ) per blow is inversely proportional to the strength of the material. Thus, higher the CBR value of a material being tested lower will be the DCP value in $\mathrm{mm} / \mathrm{blow}$. The DCP test is especially useful for bituminous pavement rehabilitation design and is being used extensively in several countries.

\section{iii) Using Benkelman Beam Deflection (BBD) \\ Plan of Study}

The structural strength evaluation of the existing pavements was carried out as per IRC 81: 1997. Pavement sections were cut open from the surface up-to the subgrade level and subgrade soil samples were collected in water proof bags for determination of moisture content and also to determine the Consistency limits.

\section{Field Studies}

The Benkelman Beam Deflection studies were carried out during September-2012 along specified stretches as per the procedure suggested by IRC: 81-1997. In each section, deflection observations were recorded along the outer wheel paths. As per the guidelines, the markings on the pavement surface were staggered. A standard truck with a rear axle load of $8170 \mathrm{~kg}$ fitted with dual tyres inflated to a pressure of $5.60 \mathrm{~kg} / \mathrm{cm}^{2}$ is made to stop such that the dual wheels are centred above the selected point. The probe of the Benkelman Beam is inserted between the dual wheels and placed on the selected point. The initial reading of the dial gauge $\left(d_{0}\right)$ is recorded. The truck is slowly driven forward by $2.7 \mathrm{~m}$ and the intermediate reading of the dial gauge $\left(\mathrm{d}_{\mathrm{i}}\right)$ is recorded. The truck is driven forward by a further $9 \mathrm{~m}$ and the final reading of the dial gauge $\left(\mathrm{d}_{\mathrm{f}}\right)$ is recorded. 
Pavement deflections are affected by seasonal variations in climate. The subgrade soil samples were collected from the wheel paths where deflection studies were conducted after digging and removing the pavement materials up to the subgrade level and collecting soil samples in airtight polythene bags and brought to the laboratory for further tests.

\section{Analysis of Data}

The Benkelman Beam deflection data obtained as per IRC: $81-1997$ was analysed. The raw data consisted of initial $\left(\mathrm{d}_{\mathrm{o}}\right)$, intermediate $\left(\mathrm{d}_{\mathrm{i}}\right)$ and final deflection $\left(\mathrm{d}_{\mathrm{f}}\right)$ values at equal intervals. The rebound deflection values obtained in each section were used to calculate the statistical parameters viz., mean and standard deviation. The characteristic deflection is taken as mean plus two times the standard deviation. Results of Geogauge, DCP and BBD are presented in Table-2

Table. 2- Results of Geogauge, DCP and BBD Studies

\begin{tabular}{|c|c|c|c|c|c|c|}
\hline \multirow[b]{2}{*}{ Section } & \multicolumn{3}{|c|}{ Geogauge } & \multicolumn{2}{|c|}{ DCP } & \multirow{2}{*}{$\begin{array}{c}\text { BBD } \\
\text { Corrected } \\
\text { Characteristic } \\
\text { Deflection, Dc } \\
(\mathbf{m m})\end{array}$} \\
\hline & $\begin{array}{c}\text { Stiffness, } \\
\text { K (MN/m) }\end{array}$ & $\begin{array}{l}\text { Elastic } \\
\text { Modulus } \\
\text { (MPa) }\end{array}$ & $\begin{array}{c}\text { CBR } \\
(\%)\end{array}$ & $\begin{array}{c}\text { DCP Value, } \\
\text { mm/blow }\end{array}$ & $\begin{array}{c}\text { CBR, \% } \\
\log _{10}(\mathrm{CBR})=2.48- \\
1.057 \log _{10}(\mathrm{DCP})\end{array}$ & \\
\hline $1^{\text {st }}$ Section & 23.86 & 207 & 173 & 0.707 & 435 & 0.931 \\
\hline $2^{\text {nd }}$ Section & 32.86 & 285 & 332 & 0.487 & 646 & 0.854 \\
\hline $3^{\text {rd }}$ Section & 36.57 & 317 & 400 & 0.446 & 715 & 0.819 \\
\hline
\end{tabular}

\section{Analysis of Stresses and Strains}

To evaluate the stresses and strains in pavement system KENPAVE Software developed by Yang H. and Huang, P.E is used. With the help of KENPAVE software the stresses and strains at critical points are evaluated by giving the necessary inputs like type of material, number of layers, number of vertical co-ordinates, system of units, thickness of layers, modulus of layers, contact radius, contact pressure and radial co-ordinates etc.

The pavement is analyzed by treating it as a four layer system, the material in each layer is assumed to be linearly elastic with poisons ratio of 0.35 for bituminous and granular materials and 0.25 for cementitious base course. The radius contact area is assumed as $15.26 \mathrm{~cm}$ which corresponds to standard wheel load of $41 \mathrm{kN}$ and contact pressure of $560 \mathrm{kPa}$. Elastic modulus for bituminous layer is taken as $2500 \mathrm{MPa}$, for granular sub-base course $200 \mathrm{MPa}$ and for subgrade soil of $5 \% \mathrm{CBR} 50 \mathrm{MPa}$ as suggested by IRC 37-2012 and for stabilized base course layer 207, 285 and $317 \mathrm{MPa}$ for $1^{\mathrm{St}}, 2^{\text {nd }}$ and $3^{\text {rd }}$ sections respectively from the field evaluation studies. Horizontal and vertical coordinates are entered to get the stresses and strains at critical points i.e at the bottom of bituminous layer and at the top of subgrade.

After entering all the inputs the vertical compressive strains at the top of subgrade and radial tensile strains at the bottom of bituminous layer are computed. The obtained strains at the critical locations are compared with the permissible strains suggested by various researchers are shown in table 3 and 4 .
Table. 3- Comparison of Permissible Subgrade Strain Values

\begin{tabular}{|c|c|c|c|}
\hline \multirow{2}{*}{$\begin{array}{c}\text { Cumulative } \\
\text { Std Axles }\end{array}$} & \multicolumn{3}{|c|}{$\begin{array}{c}\text { Subgrade Permissible Strains } \\
\text { (micro strains) }\end{array}$} \\
\cline { 2 - 4 } & PA & M S & NAG \\
& EY & $\begin{array}{c}\text { KUM } \\
\text { AR }\end{array}$ & $\begin{array}{c}\text { PRESENT } \\
\text { STUDY }\end{array}$ \\
\hline \multirow{2}{*}{$10^{7}$} & 690 & 800 & $620\left(2^{\text {nd }}\right.$ Section $)$ \\
\cline { 4 - 5 } & & & $607\left(3^{\text {rd }}\right.$ Section $)$ \\
\hline
\end{tabular}

Table. 4- Comparison of Permissible Radial Tensile Strain Values

\begin{tabular}{|c|c|c|c|}
\hline \multirow{2}{*}{$\begin{array}{c}\text { Cumulative } \\
\text { Std Axles }\end{array}$} & \multicolumn{3}{|c|}{$\begin{array}{c}\text { Permissible Radial Tensile Strains } \\
\text { (micro strains) }\end{array}$} \\
\cline { 2 - 4 } & PANDEY & $\begin{array}{c}\text { M S } \\
\text { NAGKUMAR }\end{array}$ & $\begin{array}{c}\text { PRESENT } \\
\text { STUDY }\end{array}$ \\
\hline & & & $138\left(1^{\text {st }}\right.$ \\
& & & Section) \\
\cline { 3 - 4 } $10^{7}$ & 282 & 350 & $130\left(2^{\text {nd }}\right.$ \\
& & & Section $)$ \\
\cline { 3 - 4 } & & & $128\left(3^{\text {rd }}\right.$ \\
& & & Section $)$ \\
\hline
\end{tabular}

By comparing the obtained strain values with permissible strain values, it is clear that the obtained strains are within the permissible limits of $10^{7}$ Standard Axles repetitions. Hence the study stretch can perform well for the design period of ten years.

\section{Economic Analysis}

The general idea of recycling is to improve the performance of the pavement at minimum cost. A typical economic 
analysis done for computing the conventional design and cold recycled experimental stretch constructed with RBI grade 81 by considering the cost of material, labour and equipment, cost of construction, of the various surface, base and sub-base layers as per schedule of rates 2012-13 Karnataka state PWD. Table 5 shows the comparison of cost for conventional and recycled pavement. It is found that an overall economy of $42 \%$ can be achieved by recycling and stabilizing the existing pavement.

Table. 5- Results of Economic analysis

\begin{tabular}{|c|c|}
\hline $\begin{array}{c}\text { Cost for Conventional } \\
\text { Method } \\
(\mathbf{R s}) / \mathbf{K m}\end{array}$ & $\begin{array}{c}\text { Cost for RBI treated } \\
\text { Stretch } \\
(\mathbf{R s}) / \mathbf{K m}\end{array}$ \\
\hline $1,53,50,950.00$ & $88,10,220.00$ \\
\hline
\end{tabular}

Percentage Saving $=42.60 \%$

\section{CONCLUSION}

1) The study stretch is found to be in good condition even after heavy traffic has moved for almost six months and one monsoon season.

2) The performance evaluation studies carried out from March 2012 to October 2012 indicate that the average unevenness of pavement is increased by $7.75 \%$.

3) For the test sections treated with $4 \%, 5 \%$ and $6 \%$ the elastic modulus by geogauge are 207, 285 and 317 Mpa respectively, CBR by DCP are 435, 646 and $715 \%$ respectively and deflection values by BBD are $0.931,0.854$ and $0.819 \mathrm{~mm}$ respectively. The increase in elastic modulus, CBR value and reduction in deflection values indicates better structural condition of pavement treated with higher dosage of RBI grade 81 .

4) From the strain analysis it is clear that the study stretch can perform well for the design period of ten years.

5) From the economic analysis it is found that about $42 \%$ savings can be achieved by constructing recycled pavement using RBI grade- 81 .

6) It is recommended to adopt CIR using RBI grade81 instead of reconstructing the damaged existing pavement by conventional construction practice.

\section{ACKNOWLEDGEMENTS}

The author would like to thank M/s Alchemist Touchnology Ltd. for providing the RBI Grade 81 Stabilizer and helping to evaluate the study stretch. Also I would like to thank Bruhat Bengalore Mahanagara Palike (BBMP), Bangalore for giving permission to evaluate the study stretch.

\section{REFERENCES}

1) National Cooperative Highway Research Program (NCHRP), Synthesis 421 "Recycling and Reclamation of Asphalt Pavements Using In-Place Methods", TRB, Washington D.C, 2011.

2) Anil Misra, "Resilient Moduli and Structural Layer Coefficient of fly ash Stabilized Recycled Asphalt Base" University of Missouri-Kansas City, 2007

3) Satander Kumar and Anukul Saxena., "Soil and Aggregate Stabilization for Sustainable Pavement" NBM\&CW, December 2010.

4) Anouksak Thammavong and Direk L., "Cement Stabilization of Reclaimed Asphalt Pavement Aggregate for Base Layer", Technology and Innovation for Sustainable Development Conference, Thailand, January 2006.

5) Ramzi Taha, Galalali, Adnan Basma, and Omar AlTurk, "Evaluation of Reclaimed Asphalt Pavement Aggregate in Road Bases and Sub-bases", Transportation Research Record 1652.

6) Huang,Y.H., "Pavement Analysis and Design" $2^{\text {nd }}$ edition. Pearson education Ltd., London 2004.

7) IRC, "Guidelines for Strengthening of Flexible Road Pavements Using Benkelman Beam Deflection Technique", IRC: 81-1997, Indian Roads Congress.

8) IRC, "Guidelines for the Design of Flexible Pavements", IRC: 37-2001, Indian Roads Congress.

9) IRC, "Guidelines for the Design of Flexible Pavements", IRC: 37-2012, Indian Roads Congress.

10) Nagkumar, M.S., "Stresses in bituminous pavement overlays due to variation in climatic and traffic factors" Ph.D. Thesis (unpublished) 1997, Bangalore University. 